\title{
Regression of an Epidermoid Carcinomas in Domestic Canine Treated with Casiopeína ${ }^{\circledR}$ IIgly $^{\dagger}$
}

\author{
Paola Aranda-Vargas ${ }^{1}$, Orlando Chávez-Moreno ${ }^{1}$, Sandra Rodríguez ${ }^{1}$, \\ Manuel Trejo-Mandujano ${ }^{1}$, Paola Martínez Patiño ${ }^{1}$, Lena Ruiz-Azuara ${ }^{2}$ and Carmen Mejía 1,* \\ 1 Facultad de Ciencias Naturales, Universidad Autónoma de Querétaro, \\ Campus Juriquilla C.P. 76230, Querétaro, Mexico \\ 2 Facultad de Química, Universidad Nacional Autónoma de México, C.U., \\ Ciudad de México C.P. 04510, Mexico \\ * Correspondence: maria.c.mejia@uv.es \\ + Presented at the 2nd Molecules Medicinal Chemistry Symposium (MMCS): Facing Novel Challenges in \\ Drug Discovery, Barcelona, Spain, 15-17 May 2019. \\ Published: 7 August 2019
}

Keywords: Squamous cell carcinoma; Casiopeína ${ }^{\circledR}$ IIgly; Tumoral regression

\section{Introduction}

Squamous cell carcinoma (SCC) is a malignancy that has no treatment. It develops in the scaly layer of the skin and affects the thoracic, phalangeal, and scrotal limbs, among others (Vet Pathol 2013, 50 (6): 1078). Macroscopically, it presents papillae that can ulcerate and bleed. At histological level, it shows hyperkeratosis, parakeratosis, keratin beads, and cellular pleomorphism (Ginn, 2007, pp. 748-751). On the other hand, Casiopeínas ${ }^{\circledR}$ (Cas) (Ruiz-Azuara, 1992, 1996, 2002, patent US.) have shown antineoplastic activity through mitochondrial apoptosis (Biometals 2017, (1): 43). Casiopeínas represent an important therapeutic alternative for the treatment of SCC.

\section{Objective}

To evaluate the tumor regression of a canine squamous cell carcinoma by the treatment with Casiopeína IIgly.

\section{Materials and Methods}

After diagnosis of SCC, peripheral blood and urine were collected to perform blood count, urea, creatinine, phosphorus, ALT, AST, and glucose, before and after treatment. The treatment consisted of the administration of $35 \mathrm{mg} / \mathrm{m}^{2}$ of CasIIgly i.v. for $60 \mathrm{~min}$, in $5 \%$ glucose solution. For cytology, two swabs of the lesion were taken every two hours for $6 \mathrm{~h}$. The second and third doses of CasIIgly were administered every $4 \mathrm{~h}$, and two swabs were taken just before the application of the drug. In conjunction with the treatment, a solution of $33.35 \mathrm{mg}$ of CasIIgly dissolved in $33.5 \mathrm{~mL}$ of $5 \%$ glucose solution was applied directly to the neoplasm, every $12 \mathrm{~h}$ for 27 days.

\section{Results}

We did not find changes in blood or urine, so CasIIgly did not produce systemic alterations. On the other hand, the neoplastic mass decreased its size, both in diameter and in depth, all suggestive of tumor regression. 


\section{Conclusions}

The application of CasIIgly following the treatment scheme proposed in this work is effective against CCE in dogs. However, molecular evaluations should still be done to check tumor regression.

(C) 2019 by the authors. Licensee MDPI, Basel, Switzerland. This article is an open access article distributed under the terms and conditions of the Creative Commons Attribution (CC BY) license (http://creativecommons.org/licenses/by/4.0/). 